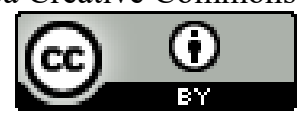

\title{
JOAQUIM CANDIDO SOARES DE MEIRELLES: UM MÉDICO NEGRO NA CORTE IMPERIAL (1797-1868)
}

\author{
Silvio Cezar de Souza Lima ${ }^{1}$
}

\begin{abstract}
Resumo: Este artigo trata da trajetória pessoal e profissional de Joaquim Candido Soares de Meirelles (1797-1868), médico cirurgião, negro, brasileiro de grande influência no Império e participante de muitos e importantes processos políticos. O Dr. Meirelles foi o idealizador e um dos fundadores da Academia Imperial de Medicina, médico da Imperial Câmara, Cirurgião-mor e Chefe do Corpo de Saúde da Armada, um dos principais reformadores do Ensino Médico no Império, além de outros atributos e títulos. Entretanto, sua carreira foi repleta de desafios, decepções e preterimentos. Desta forma, meu objetivo é mostrar como Meirelles precisou lutar por direitos à cidadania dos "Homens de Cor" e superar barreiras impostas por adversários políticos e pelo racismo para construir sua trajetória intelectual e política.
\end{abstract}

Palavras chave: Intelectuais Negros; História dos Negros no Brasil; História da Medicina; Império; Médicos Negros.

\section{JOAQUIM CANDIDO SOARES DE MEIRELLES: A BLACK DOCTOR AT THE IMPERIAL COURT (1797-1868)}

Abstract: This article focuses on the personal and professional trajectory of Joaquim Candido Soares de Meirelles (1797-1868), Surgeon, Black and Brazilian, of great influence on the Empire and part of various and important political processes. Dr. Meirelles was the idealizer and one of the founders of the Imperial Academy of Medicine, the Imperial Chamber of Medics, Chief Surgeon and Leader of the Marine Health Corps, one of the main reshapers of the Medical Teachings in the Empire, as well as many other titles and attributes. However, his career was full of challenges, disappointments and abandonments. Thus, my objective is to show how Meirelles had to fight for the citizen rights of "Men of color" and overcome barriers imposed by political opponents and racism, to construct his own intelectual and political path.

Keywords: Black Intellectuals; History of Blacks in Brazil; History of Medicine; Empire; Black Doctors.

\footnotetext{
${ }^{1}$ Professor Adjunto na Universidade Federal Fluminense (UFF), atua no Laboratório de Pesquisa e Ensino em História (LAPEH) do Departamento de Ciências Humanas (PCH) da UFF. ORCID: https://orcid.org/0000-0002-5422-7214. E-mail: silviocslima@ gmail.com
}

Revista da ABPN • v. 12, n. Ed. Especial - Caderno Temático: "Africanos, escravizados, libertos biografias, imagens e experiências atlânticas” • agosto de 2020, p. $320-343$ 


\section{JOAQUIM CANDIDO SOARES DE MEIRELLES: UN MÉDICO NEGRO EN LA CORTE IMPERIAL (1797-1868)}

Resumen: Este artículo trata sobre la trayectoria personal y profesional de Joaquim Candido Soares de Meirelles (1797-1868), médico cirujano, negro, brasileño de gran influencia en el Imperio y participante en muchos procesos políticos importantes. El doctor Meirelles fue el idealizador y uno de los fundadores de la Academia Imperial de Medicina, médico de la Cámara Imperial, Jefe de Cirujanos y Jefe del Cuerpo de Salud de la Armada, uno de los principales reformadores de la Educación Médica en el Imperio, además de otros atributos y títulos. Sin embargo, su carrera estuvo llena de desafíos, decepciones y deprecaciones. De esta forma mi objetivo es mostrar como Meirelles necesitó luchar por derechos a la ciudadanía de los "Hombres de Color" y superar las barreras impuestas por los opositores políticos y el racismo para construir su trayectoria intelectual y politica.

Palabras-clave: Intelectuales negros; Historia de los negros en Brasil; Historia de la medicina; Imperio; Doctores negros

\section{JOAQUIM CANDIDO SOARES DE MEIRELLES: UN MÉDECIN NOIR À LA COUR IMPÉRIALE (1797-1868)}

Résumé: Cet article présente la trajectoire personnelle et professionnelle de Joaquim Candido Soares de Meirelles (1797-1868), chirurgien, noir, brésilien avec une grande influence dans l'Empire et participant à de nombreux processus politiques importants. Dr Meirelles a été l'idéalisateur et l'un des fondateurs de l'Académie impériale de médecine, médecin de la Chambre impériale, chirurgien en chef et chef du Corps de santé de l'Armée, l'un des principaux réformateurs de l'éducation médicale dans l'Empire, en plus il a eu d'autres attributs et titres. Toutefois, sa carrière a été pleine de défis, de déceptions et renoncements. De cette façon, mon but est de montrer comment Meirelles a dû se battre pour les droits de citoyenneté des « hommes de couleur » et surmonter les barrières imposées par les opposants politiques et le racisme pour construire sa trajectoire intellectuelle et politique.

Mots-clés: Intellectuels noirs; Histoire des Noirs au Brésil; Histoire de la médecine; Empire; Médecins noirs.

\section{REPARAR AS INJUSTIÇAS DE CLIO}

Nos Estudos Históricos, muitas vezes a ausência é mais significativa do que a presença. Desta feita, saltam aos nossos olhos a ausência de intelectuais negros na historiografia brasileira. Esta lacuna não está relacionada à inexistência de homens e mulheres negras em atividades intelectuais. Ela está muito mais atrelada a um desejo de

Revista da ABPN • v. 12, n. Ed. Especial - Caderno Temático: "Africanos, escravizados, libertos biografias, imagens e experiências atlânticas" • agosto de 2020, p. $320-343$ 
branqueamento da sociedade, ou ainda, ao lugar social do negro no imaginário nacional, incluindo nesta a própria comunidade científica. Assim, ficam invisibilizados médicos, engenheiros, filósofos, naturalistas e uma multiplicidade de intelectuais esquecidos na tessitura da História brasileira (Gomes e Domingues, 2018 p. 6-7). Nos cabe então um esforço de pesquisa coletivo para reparar as "injustiças de $\mathrm{Clio}^{2}$ " e trazer novamente ao centro do palco atores sociais esquecidos.

É inegável que durante a escravidão, em pleno século XIX, existiu um relevante número de intelectuais negros no império brasileiro. Os maiores exemplos são os irmãos engenheiros Rebouças, o poeta Cruz e Souza, o escritor Machado de Assis, o jornalista José do Patrocínio, o advogado Luiz Gama, entre outros influentes intelectuais negros no Brasil oitocentista. Se compararmos o número de bacharéis "de cor" das primeiras décadas da república (Carvalho, 2008, p.313), com o período imperial, é interessante como mesmo num país escravocrata, muitos negros ocuparam posições de destaque e tiveram voz e influência na corte. Apesar desta constatação, também é igualmente surpreendente que a cor destes intelectuais tenha se invisibilizado com o passar do tempo.

Um bom ponto de partida é uma melhor compreensão da relação entre negros e ciência, em especial a ciência brasileira. Apesar de considerar a importante contribuição africana para a tecnologia agrícola e siderúrgica e reconhecer os avanços relacionados aos saberes tradicionais de cura, precisamos avançar mais: o negro brasileiro também estava inserido no campo científico à partir dos saberes ocidentais, a partir dos saberes considerados científicos e nos espaços formais de ciência em posição de destaque. Trazer à tona toda a importância da trajetória do Dr. Joaquim Cândido Soares de Meirelles é trazer a discussão da importância do negro na implementação da medicina ocidental moderna no Brasil Império.

As investigações e reflexões em torno da trajetória deste médico e político negro, ajudarão a pensar nas formas pelas quais ele buscou inserção social ainda que sob as estruturas sociais escravistas e excludentes do período imperial. Até que ponto é possível enxergar na agência desse sujeito um movimento capaz de interferir nessas estruturas? Ou, por outro lado, o que pode nos revelar sua carreira acadêmica, profissional e política, suas experiências de intelectual negro num mundo de valores brancos e senhoriais?

\footnotetext{
${ }^{2}$ Parafraseando o título do livro de Clóvis Moura, As injustiças de Clio: o negro na historiografia brasileira.
}

Revista da ABPN • v. 12, n. Ed. Especial - Caderno Temático: "Africanos, escravizados, libertos biografias, imagens e experiências atlânticas" • agosto de 2020, p. $320-343$ 
Pensar a trajetória pessoal e profissional do Dr. Meirelles, no contexto imperial, ajuda no processo de compreensão das trajetórias de outras negras e negros no contexto brasileiro. (Gomes e Domingues, 2018, p.5)

A trajetória profissional e pessoal de uma pessoa é influenciada por uma série de fatores, contexto histórico, visão de mundo, marcadores sociais e grupos sociais dos quais participa. No caso de Meirelles podemos perceber o quanto sua condição de "homem de cor" no império brasileiro, cuja dinâmica sócio econômica estava marcada pela escravidão atlântica, é um fator relevante para pensar sua vida. Não é possível construir a trajetória pessoal do médico fundador da Academia Imperial de Medicina e um dos principais personagens no processo de institucionalização da medicina no império sem observar o quanto sua percepção de si como "mulato" e da sociedade e instituições da qual fez parte nas contradições de ser um homem negro, intelectual e político em um mundo dominado por brancos.

\section{OS ANOS DE FORMAÇÃO ACADÊMICA E PROFISSIONAL}

Meirelles nasceu em Santa Luzia do Sabará, na província de Minas Gerais, em 5 de novembro de 1797. Filho do Cirurgião Manoel Soares de Meirelles e de Anna Joaquina de São José Meirelles. Vinha de uma família de cirurgiões: seu avô teria se formado em Coimbra e seu bisavô Luiz de Meirelles foi um médico na cidade de Porto. Apesar de ser conhecida na região, sua família tinha uma posição social modesta.

Quando teve idade para iniciar os estudos secundários, foi enviado para o Rio de Janeiro sob os cuidados de seu abastado tio, o padre João Baptista Soares de Meirelles, latinista e professor do Seminário de São José. Graças ao tio, Meirelles estudou Humanidades neste Seminário. Após o Seminário fez os exames e ingressou para a Academia Médico-Cirúrgica do Rio de Janeiro em 1817. A partir do seu histórico familiar, é possível notar que a educação foi uma das estratégias de ascensão social da família de Meirelles. E em seu campo de possibilidades estava a formação de Cirurgião, profissão de seu pai e ancestrais.

Durante os estudos na Academia médico-Cirúrgica, o jovem Meirelles ingressa no $1^{\circ}$ batalhão de Caçadores da Corte como ajudante de cirurgia, em 1819 (Souto,1935).

Revista da ABPN • v. 12, n. Ed. Especial - Caderno Temático: "Africanos, escravizados, libertos biografias, imagens e experiências atlânticas" • agosto de 2020, p. 320-343 
Neste período, era pensionário do Hospital Real Militar, onde funcionava a Escola Anatômica Cirúrgica e Médica do Rio de Janeiro. Seu cotidiano como estudante girava em torno do aprendizado teórico e prático, somado ao trabalho como ajudante de cirurgia e ainda os serviços no Hospital Real Militar, que também era sua residência. Esta severa rotina lhe propiciou muita experiência, algo imprescindível para a carreira de um bom cirurgião. Tanto que prestou os exames e após ser aprovado, recebeu a carta de cirurgião em 1822 .

Depois de cinco anos no Hospital Real Militar, onde morava, trabalhava e estudava, já recém-formado, solicitou a vaga de Cirurgião Mor. O requerimento não foi atendido. Entretanto, Meirelles não aceitou a recusa e fez uma petição direta ao imperador. Em sua carta, questionou os motivos do indeferimento para o cargo de cirurgião mor de seu batalhão. Argumentou que teve uma formação dedicada e com conteúdo acima dos necessários para o cargo. Afirmou que nunca faltara às aulas, e alegou ter sido preterido por outro cirurgião ajudante, cuja formação e dedicação tanto aos estudos quanto aos serviços médicos seriam qualitativamente inferiores aos seus. Relatou ao imperador que, por ser pensionário "do Hospital Militar, onde morava lá curava com duplicado trabalho" durante os últimos cinco anos, ininterruptamente, ao contrário do seu colega que fora promovido a Cirurgião Mor e de outros estudantes. Como estes realizavam suas práticas médicas no Hospital da Santa Casa de Misericórdia, eles eram praticamente dispensados nos períodos de férias. Meirelles reclamou sobre "o modo, porque se procuram lugares os homens e não homens para os lugares" e solicitou ao imperador a revisão da decisão do Cirurgião Mor do Exército. (Souto, 1935, p.30).

O requerimento foi acompanhado de uma carta do Comandante do seu Batalhão, com elogios e ratificando os argumentos e Meirelles. Seu comandante reforçou a necessidade de promoção do ajudante, tendo em vista que ele estava já há seis meses substituindo o cirurgião do batalhão que se encontrava em uma expedição na Bahia, de onde provavelmente não retornaria. Parece que era do interesse do comandante que Meirelles assumisse de maneira permanente o cargo, pois em carta que seguia anexa à petição ao Imperador ressaltou o empenho e profissionalismo do requerente.

Meirelles foi finalmente promovido para cirurgião Mor em junho de 1823 . No entanto, essa promoção veio acompanhada da sua transferência para o Regimento de

Revista da ABPN • v. 12, n. Ed. Especial - Caderno Temático: "Africanos, escravizados, libertos biografias, imagens e experiências atlânticas” • agosto de 2020, p. $320-343$ 
Cavalaria de linha de Minas Gerais, sua província natal, tendo assim que deixar seu Batalhão na Corte do Rio de Janeiro.

Em Minas Gerais, o jovem cirurgião Mor pôde demonstrar suas habilidades organizando o Hospital Militar de Ouro Preto e combatendo duas epidemias que assolaram a cidade naquele período. O seu zelo no trato dos pacientes fez a população da cidade solicitar o retorno deste a Minas, quando foi requisitado para resolver assuntos na Corte Imperial (Souza, 1986; Souto, 1935 e Macedo, 1876). Seu desempenho profissional provavelmente foi o principal fator que motivou sua indicação como um dos quinze oficiais do Exército pensionistas do Governo Imperial enviados à Europa, para complementar seus estudos e conhecimentos técnicos ${ }^{3}$.

Qualquer luso brasileiro com desejos de seguir a carreira como médico precisava sair do país para estudar, pois a Academia Médico Cirúrgica não oferecia a formação em Medicina. Este quadro se alterou com a reforma do Ensino Médico em 1832 quando essa Academia se tornou Faculdade de Medicina do Rio de Janeiro. Desta forma, era algo raro alguém nascido na América portuguesa estudar medicina durante o período colonial e nas duas primeiras décadas do Império. Para estudar medicina era necessário escolher alguma universidade europeia, o que tornava esta formação quase exclusividade dos filhos das elites luso-brasileiras. Ser designado para estudar no exterior pelo Estado era uma grande oportunidade de ascensão profissional. Meirelles se matriculou na Faculdade de Medicina de Paris, onde estudou com alguns dos principais nomes das Ciências Médicas de sua época.

No exterior, teve uma vida extremamente regrada, passando por restrições financeiras e ocupando todo o seu tempo com os estudos. Segundo Joaquim Manuel de Macedo (1876), Meirelles narrava assim o seu período em Paris:

Já eu era marido e pai, da minha pensão de cinquenta mil réis fortes deixei metade para minha mulher e filhos, e com os vinte e cinco mil fortes que me ficaram, tive, além do mais, de pagar mestres e de comprar livros e cadáveres: durante os

\footnotetext{
${ }^{3}$ É importante destacar que alguns biógrafos atribuem a escolha de Meirelles por sua participação nos eventos relacionados à permanência de D. Pedro no Brasil em janeiro de 1822. Foi ele o jovem militar que foi ao teatro avisar ao jovem príncipe regente que as tropas portuguesas lideradas por Avilez estavam a caminho com o intuito de prendê-lo e levá-lo para Lisboa (Liberalli, 1969). Não descarto esta hipótese, no entanto, o mesmo imperador não o nomeou para o cargo desejado de cirurgião Mor no Rio de Janeiro, em seu batalhão de origem, logo considero esta hipótese menos provável que a ideia do mérito.
}

Revista da ABPN • v. 12, n. Ed. Especial - Caderno Temático: "Africanos, escravizados, libertos biografias, imagens e experiências atlânticas” • agosto de 2020, p. $320-343$ 
dias uteis da semana alimentava-me ordinariamente, comendo frutas, e pão: aos domingos desforrava-me da penitência, indo jantar com Paulo Barbosa, ou com José Marcellino Gonçalves, ou com o capitão-mor José Joaquim da Bocha, ou com o visconde de S. Lourenço, e então eram para mim inapreciáveis, maviosíssimos esses dias de festa, porque neles o excelente jantar era o menos, o falarmos da pátria era o mais (MEIRELLES apud. MACEDO, 1876 p.365).

Em dois anos, cursando as disciplinas necessárias na Faculdade de Medicina de Paris e com o aproveitamento dos estudos feitos anteriormente na Academia Médico Cirúrgica do Rio de Janeiro, apresentou duas teses, formando-se simultaneamente em Medicina e Cirurgia em 1827. Sua tese em medicina: Dissertation sur l'historie de l'Eléphantiasis, tinha como assunto a doença conhecida como Elefantíase dos Gregos, Mal de São Lazaro ou Morféia. Esta despertava grande interesse dos praticantes das artes de curar no Brasil e que acometia principalmente a população de escravizados e pretos e pardos livres. A banca examinadora foi presidida por Balthasar-Anthelme Richeland e teve como componentes os professores Pierre Eloi Fouquier, Guillaume Dupuytren, Hyppolyte Cloquet e Germain-Jules Cloquet.

Em sua tese em cirurgia, o assunto lhe era familiar devido aos anos de serviço em Hospitais militares: Dissertation sur les plaies d'armes à feu. A tese, sobre ferimentos ocasionados por armas de fogo era de particular interesse para os cirurgiões do exército ${ }^{4}$. Esta banca foi presidida por um dos maiores cirurgiões da frança, Guillaume Dupuytren e participaram os professores Joseph- Claude-Anthelme Recamier, Jules Cloquet, Philippe Boyer, Hippolyte Cloquet e Sauver-Henri-Victor Bouvier (Souza, 1986).

Meirelles retornou ao Brasil em 1827, com a dupla formação pela Faculté de Médicine de Paris em apenas dois anos. Motivado pelos seus êxitos acadêmicos, o Doutor Meirelles solicitara a nomeação para inspetor dos hospitais militares, o que lhe foi negado, "por não satisfazer uma pequena nuga regulamentar que tal impedia" (Souto, 1935, p. 49). Alegando dificuldades para manter a família com o soldo de Cirurgião, pediu demissão do Exército em 1828. Passou a se dedicar a sua clínica particular (que devido a sua boa reputação neste momento movimentava uma boa clientela) e a enfermaria da

\footnotetext{
${ }^{4}$ Acontecia naquele período a Guerra Cisplatina e Meirelles então enviou para o governo 40 exemplares de sua tese para distribuir entre os jovens cirurgiões, que não tinham experiência com ferimentos sofridos no campo de batalha.
}

Revista da ABPN • v. 12, n. Ed. Especial - Caderno Temático: "Africanos, escravizados, libertos biografias, imagens e experiências atlânticas” • agosto de 2020, p. $320-343$ 
Santa Casa de Misericórdia do Rio de Janeiro que dividiu com o Dr. Luis Vicente De Simoni, Médico italiano instalado no Brasil desde 1817.

Na Santa Casa, o Dr. Meirelles protagonizou um episódio que gerou debate público e que além de nos evidenciar a percepção de parte da população sobre relações raciais e cidadania, também ajudou a construir para ele uma imagem que o acompanhou por boa parte de sua vida. Uma carta ao jornal Astrea deu início ao debate público entre o médico e o inimigo das diferenças de cor e nos trouxe o incidente na Santa Casa.

Na edição de 22 de setembro de 1829 foi publicada a carta de um leitor que reclamava do tratamento recebido na enfermaria da Santa Casa pelo seu empregado. O queixoso era "um crioulo forro de Minas" que fora tratar uma febre. Depois de alguns dias de tratamento entraram na enfermaria "uns homens de comenda" e trocaram os doentes de camas dizendo que os brancos deveriam de ficar em um lado da enfermaria e os pretos do outro. Afirmou que, "uns diziam que era bom ficar os escravos sós, e os livres sós; porém outros disseram que uma vez que eram pretos que ficassem todos juntos" (Astrea, 1829, n. 474, p.1). O doente achou tudo aquilo um desrespeito, pediu alta e relatou o ocorrido ao seu empregador, com o desabafo: “Ora veja Vossa Mercê! Eu apesar de ser preto, nunca fui escravo de ninguém, meus pais, ainda que pobres, me deram a educação que estava a seu alcance" (Astrea, idem).

Em sua queixa ao jornal, o autor da carta questionava a Santa Casa sobre os direitos dos homens livres, resguardados pela Constituição do Império, que "não estabelece diferenças entre os cidadãos, senão aquelas provenientes dos talentos e da virtude”. E finalizou questionando o posicionamento dos médicos que deveriam de "professar sentimentos de igualdade" e aconselhar aos administradores do hospital evitando tal escândalo. Por fim, dizia-se admirado ao saber que tudo aconteceu na enfermaria do "Doutor Meirelles, que se passa por muito constitucional, amigo da lei e da igualdade do homem" e fez críticas ao médico demonstrando desapontamento com a sua inércia (Astrea, idem).

Na edição seguinte, Meirelles respondeu a carta, e relatou os acontecimentos a partir de seu ponto de vista. Ele narrou que o provedor da Santa Casa lhe dissera que era necessário arrumar os doentes e separar os livres dos escravizados, ação com a qual concordou. Entretanto, o Cirurgião Mor da Santa Casa de Misericórdia, Jeronimo Alves

Revista da ABPN • v. 12, n. Ed. Especial - Caderno Temático: "Africanos, escravizados, libertos biografias, imagens e experiências atlânticas” • agosto de 2020, p. 320-343 
de Moura dissera que seria melhor que todos os pretos ficassem de um lado e os brancos de outro. Esta conversa acontecia sob o testemunho de Luis De - Simoni o outro médico da enfermaria e alguns alunos que concordavam com Meirelles, que replicou que aquela seria uma divisão odiosa e saiu indignado. Quando retornou no dia seguinte, os pacientes estavam divididos pela cor. Indagou ao enfermeiro e este lhe disse, desculpando-se que recebera ordens de seus superiores. O médico relatou que procurou novamente o provedor e este dissera que fora determinado pela mesa diretora e deveria permanecer como estava (Astrea, n. 475, 1829).

Este evento demonstrou num debate público o quanto parte dos pretos e mulatos estavam conscientes de sua cidadania no primeiro reinado (KRAAY, 2015). Foram três correspondências sobre o tema, mas aparentemente a polêmica não ficou apenas no jornal: Alguns meses depois do incidente, Meirelles pediu demissão da Santa Casa, possivelmente pelo desgaste ocorrido tanto para ele quanto para a instituição. E sua publicação naquele periódico possivelmente construiu a imagem de Meirelles como defensor da igualdade de direitos entre negros e brancos que mais tarde lhe renderia a acusação de criar uma sociedade secreta com o objetivo de fomentar na corte uma revolta nos moldes do Haiti (Morel, 2017). Mas antes desta, tratemos da fundação de uma outra Sociedade.

\section{A FUNDAÇÃO DA SOCIEDADE DE MEDICINA DA CORTE}

Foi na Santa Casa entre as conversas, entrevistas diárias e conferências com o Doutor De Simoni ${ }^{5}$, que surgiu a ideia de criação de uma agremiação "que promovesse no país o gosto pelos estudos médicos e os interesses e progressos da ciência” (De Simoni, 1868, p. 292). A ideia também entusiasmou o Dr. José Martins da Cruz Jobim6 que foi

\footnotetext{
${ }^{5}$ Luiz Vicente De Simoni afirma ter se tornado um grande amigo de Meirelles neste período de convivência no Hospital da Santa Casa. Ele foi responsável pelo discurso fúnebre em homenagem ao amigo em sua missa de sétimo dia na igreja da Ordem Terceira do Carmo em 20 de julho de 1868.

${ }^{6}$ Cruz Jobim nasceu em 1802, formou-se Doutor em Medicina 1828 na faculdade de Medicina de Paris. Foi professor da Faculdade de Medicina do Rio de Janeiro e Senador do Império In: JOBIM, José Martins da Cruz. Dicionário Histórico-Biográfico das Ciências da Saúde no Brasil (1832-1930). Capturado em 28 nov. 2002. Online. Disponível na Internet http://www.dichistoriasaude.coc.fiocruz.br/iah/pt/verbetes/jobimjmcr.htm sobre Jobim ver também LIMA, Silvio Cezar de Souza. Cruz Jobim e as doenças da classe pobre. O corpo
}

Revista da ABPN • v. 12, n. Ed. Especial - Caderno Temático: "Africanos, escravizados, libertos biografias, imagens e experiências atlânticas" • agosto de 2020, p. $320-343$ 
seu contemporâneo na faculdade de Medicina de Paris e juntos assistiram algumas das reuniões da Academia de Medicina francesa. Jobim trabalhava na Santa Casa na enfermaria vizinha a de Meirelles e De Simoni fato que provavelmente ajudou a consolidar os planos de fundação da Sociedade. Convidaram também os médicos franceses que viviam na corte imperial, Jean François Xavier Sigaud ${ }^{7}$ e Jean Maurice Faivre $^{8}$ (Fernandes, 1982).

A primeira reunião foi realizada à noite, na casa de Sigaud, na Rua do Rosário, 185 no dia 28 de maio de 1829 (Souto, 1935) onde este ficou encarregado de escrever os estatutos da sociedade e foi o editor do primeiro periódico da instituição, O Semanário de Saúde Pública, publicado nos anos 1831-1833 (Semanário de Saúde Pública, n.1, 1831). As reuniões preparatórias posteriores foram realizadas na residência de Meirelles na rua da cadeia, $161^{9}$ entre os dias 4 e 25 de junho e no dia 30 de junho de 1829 , foi realizada a sessão de instalação da Sociedade de Medicina. Meirelles foi eleito o $1^{\circ}$ presidente daquela agremiação.

A Sociedade de Medicina em pouco tempo se tornou órgão consultivo do governo imperial para as questões relacionadas à saúde pública. Em 1835, por influência de Meirelles, é elevada a Academia Imperial de Medicina (Souto, 1935). Agregando os principais expoentes da medicina do Império, foi também responsável pela institucionalização da medicina no Brasil ${ }^{10}$. Esta agremiação teve papel fundamental na reforma do ensino médico brasileiro, sendo a atuação de Meirelles preponderante para trazer este importante encargo para a Academia.

escravo e a produção do conhecimento médico na Primeira metade do século XIX. Almanack, Guarulhos, n. 22, p. 250-278, Aug. 2019.

${ }^{7}$ Jean François Xavier Sigaud nasceu em Marseille em 1796, doutorou- se em Medicina em 1818 na Faculté de Médecine de Strasbourg. Foi Editor de Periódicos médicos e literários e Médico da Imperial Câmara. SIGAUD, José Francisco Xavier. Capturado em 28 nov. 2002. Online. Disponível na Internet http://www.dichistoriasaude.coc.fiocruz.br/iah/pt/verbetes/sigjoxav.htm Sobre Sigaud, ver também FERREIRA, Luiz Otávio. José Francisco Xavier Sigaud: um personagem esquecido, uma obra reveladora. História, Ciências, Saúde-Manguinhos, Rio de Janeiro, v.V, n.1, p.125-126, mar./jun.1998.

${ }^{8}$ Jean Maurice Faivre nasceu em 1795 em Jura na França e formou- se em Medicina em 1825 Em 1826, vem para o Brasil, onde se torna médico da $7^{\mathrm{a}}$ Enfermaria no Hospital Militar da Corte.

${ }^{9}$ Atual rua da Assembleia.

${ }^{10}$ Sobre o processo de institucionalização da medicina no Brasil e a Academia Imperial de Medicina, ver: Kury, 1990 e Ferreira, 1996.

Revista da ABPN • v. 12, n. Ed. Especial - Caderno Temático: "Africanos, escravizados, libertos biografias, imagens e experiências atlânticas” • agosto de 2020, p. $320-343$ 
O médico formado pela Faculdade de Medicina de Paris, José Lino Coutinho deputado e professor da Academia Médico Cirúrgica da Bahia apresentara um projeto de reformulação do ensino médico brasileiro no Parlamento. Este projeto foi criticado por Meirelles na imprensa e, por conta da repercussão negativa, cria-se um impasse entre os deputados. A vista disso, a Câmara solicitou a Sociedade de Medicina a elaboração de um anteprojeto de reforma do Ensino Médico. A incumbência foi aceita e uma comissão formada, tendo o Dr. Cruz Jobim como relator. Tempos depois foi apresentado o "Plano de organização das Escolas de Medicina do Rio de Janeiro e Bahia”, sendo aprovado quase sem alterações. (Fernandes, 1982)

Nota-se que foi fundamental a participação do Dr. Meirelles na articulação da opinião pública, conseguindo levar para a Sociedade de Medicina a incumbência de reestruturação do Ensino Médico que culminou na criação das Faculdades de Medicina do Rio de Janeiro e da Bahia. Apesar de todo o seu mérito como Médico e esforço político, não conseguiu ser Lente ${ }^{11}$ da Faculdade de Medicina do Rio de Janeiro (Souto, 1935). O próprio Meirelles relatou este desgosto já em sua velhice em carta ao Marquês de Olinda. Após a aprovação da lei da reforma do ensino médico de 1832, alguns médicos e cirurgiões solicitaram as cadeiras de Lentes da recém criada Faculdade de Medicina. Meirelles mesmo solicitou a cadeira de Clínica Cirúrgica, Cristóvão José dos Santos a de Medicina Operatória, entre outros solicitantes. Segundo o relato do Dr. Meirelles, o Ministro do Império Nicolau Pereira de Campos Vergueiro nomeou por decreto o seu médico e de sua família, Joaquim José da Silva, e pôs todas as outras cadeiras a concurso (Cunha, 2004). Dr. Meirelles chama atenção que a cadeira solicitada por ele ficou vaga pelo concurso e depois foi ocupada por nomeação. Como relato que se segue:

\begin{abstract}
"Depois soube-se que essa Cadeira estava reservada para certo estudante que estava em França formando-se em Medicina. Aqui chegando em 1833 ou 34, se lhe disse: "A Cadeira tal está guardada para ti"... Em virtude de toda esta cotterie fiquei fora da Escola de Medicina, e por isso sem direito a ter o título do Conselho!.” (MEIRELLES apud CUNHA, 2004, p.40).
\end{abstract}

\footnotetext{
${ }^{11}$ Lente é sinônimo de Catedrático. É como se denominava o professor responsável pela disciplina no século XIX.
}

Revista da ABPN • v. 12, n. Ed. Especial - Caderno Temático: "Africanos, escravizados, libertos biografias, imagens e experiências atlânticas” • agosto de 2020, p. $320-343$ 
O Dr. Meirelles possuía um currículo excepcional, ostentava tanto o título de doutor em Medicina quanto em Cirurgia, duas teses e muitos anos de experiência. Era possível perceber nos quadros da faculdade professores com currículos menos robustos que o dele, entretanto as preferências políticas e pessoais, além de outros critérios pouco confessáveis, deixaram o médico fora do corpo docente daquela instituição. Em contrapartida, Meireles fora nomeado Lente de Anatomia e Fisiologia das Paixões da Academia Imperial de Belas Artes e nela lecionou de 1836 a 1856, "uma instituição de muito menor prestígio, frequentada exclusivamente pelos filhos de artesãos, pequenos comerciantes e até mesmo, ex-escravos." (Ferreira, 1996, p.83)

\section{AS ACUSAÇÕES DE HAITIANISMO}

O ano de 1831 foi marcado por intensas movimentações políticas. A abdicação de Dom Pedro I ao trono imperial em 7 de abril iniciou o conturbado período regencial que foi marcado por disputas políticas acirradas e diversas rebeliões populares (Morel, 2003). Além disso cabe ressaltar as discussões sobre o tráfico transatlântico de escravos, que culminou com a sua proibição em novembro de 1831. Neste conturbado contexto político, Meirelles foi envolvido em uma séria intriga que o assombraria por décadas e que consolidaria no Brasil uma ideia que persistiu até o fim da escravidão: o medo da Revolução do Haiti.

"Um boato corre, há dias, pela cidade que tem enchido a uns de pavor e outros de indignação, em cujo último número me coloco" (Meirelles apud Souto, 1935, p. 128) ${ }^{12}$. Assim Meirelles descreveu seu sentimento em carta ao cirurgião José Joaquim da Silva questionando - o sobre os rumores que se espalharam rapidamente pela cidade. Realmente a população tinha motivos para se assustar ${ }^{13}$ dado o teor das graves acusações que eram feitas. O fundador da Sociedade de Medicina do Rio de Janeiro era acusado de criar um

\footnotetext{
12 Trecho de carta escrita por Meirelles e enviada à Joaquim José da Silva em 3 de junho de 1831. Ela foi publicada no folheto: Explicação da intriga feita pelo Cirurgião formado Joaquim José da Silva ao Dr. Joaquim Cândido Soares de Meirelles. Publicado por Joaquim Candido Soares de Meirelles em 1831. O folheto foi integralmente reproduzido em SOUTO, 1935.

${ }^{13}$ Segundo Marco Morel, ocorreu "um Grande Medo" na capital do império pelos rumores de uma possível ação nos moldes da Revolução do Haiti (MOREL,2017)
}

Revista da ABPN • v. 12, n. Ed. Especial - Caderno Temático: "Africanos, escravizados, libertos biografias, imagens e experiências atlânticas” • agosto de 2020, p. $320-343$ 
clube secreto com influências das ideias do Abade Gregoire ${ }^{14}$, cuja objetivo era fomentar no Brasil uma revolução de escravos e livres pretos e mulatos, nos moldes da Revolução do Haiti.

É importante neste momento explicar aos leitores a dinâmica da divulgação da polêmica. Cada envolvido na trama publicou um folheto. O primeiro foi escrito por Meirelles, com o objetivo de defender-se das acusações e dissolver os boatos: Exposição da intriga feita pelo cirurgião formado Joaquim José da Silva ao Doutor Joaquim Candido Soares de Meirelles (1831). Depois Silva publica a sua versão do ocorrido, agora acusando diretamente Meirelles, mobilizando testemunhas a apresentando explicações à população em seu: O cyrurgião formado Joaquim José da Silva ao público (1831) e por último a versão de Jacintho Rodrigues Pereira Reis: Reflexões às Calumnias tecidas pelo cirurgião formado Joaquim José da Silva (1831). Eles foram analisados por José Vieira Fazenda, sob o título "Sociedade Gregoriana" (FAZENDA, 1927). Os três folhetos circularam pela cidade e o boato foi debatido nos diversos jornais do império por anos. Esta polêmica consolidou o termo Haitianismo no vocabulário político do império (MOREL, 2017) e como ideia, foi largamente utilizada para promover o controle social e político sobre a população negra, livre ou escravizada.

Até o momento, encontrei poucas informações sobre Joaquim José da Silva disponíveis ${ }^{15}$. Sabemos que Silva era cirurgião formado, era do partido liberal próximo de Nicolau Pereira de Campos Vergueiro, porém do grupo exaltado. Joaquim José da Silva foi professor da Faculdade de Medicina do Rio de Janeiro, conforme citado anteriormente. Segundo relato de Silva, um dia encontrou o Dr. Meirelles na rua e este o puxou para um estábulo, para se protegerem do sol e dos ouvidos alheios. Ali o médico queixou-se dos brancos ameaçando vingança e fizera o convite para a tal sociedade que teria por finalidade assassinar os brancos e cruzamento das raças. Aterrorizado ao ouvir nomes de pessoas muito estimadas, afirmou Silva que dissimulara interesse para que pudesse saber os planos e sabotá-los.

\footnotetext{
${ }^{14}$ Henri Gregoire (1750-1831) foi religioso e político. Um dos principais líderes da Revolução Francesa. Gregoire foi um grande apoiador e teve atuação marcante na Revolução do Haiti, além de ser um defensor do abolicionismo. Sobre o Abade Gregoire, ver (MOREL, 2017)

${ }^{15}$ Este artigo foi produzido no contexto da pandemia de COVID-19, em isolamento social. Não foi possível acessar documentação de arquivos para buscar informações importantes para o enriquecimento da análise.
}

Revista da ABPN • v. 12, n. Ed. Especial - Caderno Temático: "Africanos, escravizados, libertos biografias, imagens e experiências atlânticas” • agosto de 2020, p. $320-343$ 
Joaquim da Silva também o acusava de enviar emissários às fazendas para seduzir escravizados, os convencendo à rebelião. E alertou ao Governo Imperial para que tomasse precauções com a fazenda do marquês de Baependi, pois "um dos sócios nomeados pelo monstro (Meirelles) costumava visitá-la quinze e mais dias, e provavelmente lhe seduziria os escravos. Pusessem estes (escravos) em confissão, e nomeariam o sr. Jacintho" (FAZENDA, 1927, v.4, p. 290).

O citado "cumplice" era Jacintho Rodrigues Pereira Reis, também cirurgião e cunhado do Dr. Meirelles. Foi diretor do Instituto Vacínico do Império e posteriormente diretor do Instituto Hahnemanniano do Brasil e seu primeiro presidente. Também teve intensa participação política no império, ligado ao partido liberal. ${ }^{16}$ Jacintho Reis tinha muita proximidade com Meirelles e sua família. Foi sob influência deste que Saturnino, filho de Meirelles se tornou médico homeopata (SOUTO, 1935).

Os rumores espalhados sobre a Sociedade Gregoriana e um eminente surgimento de revoltas escravas era potencialmente devastador para a credibilidade pessoal e consequentemente para a carreira de Meirelles. Ele defendeu-se das acusações de diversas formas, dentre elas publicando carta no Aurora Fluminense, influente periódico editado por Evaristo da Veiga (MOREL, 2017). Na missiva questionou os boatos e em certos momentos usou da ironia para mostrar os absurdos das acusações, como a de enviar livros sobre a revolução do Haiti para escravizados:

Eles me apontam como chefe da rebelião africana, dizendo que tenho relações com os Haitianos; que aqui se acham dois; que vieram tratar comigo sobre a insurreição; que eu mandei imprimir quatro mil exemplares da História do Haiti para se distribuir pelos Africanos (não sei se mesmo em Francês, ou a tradução, que valerá o mesmo) que o plano que tenho dado, é o extermínio, o assassinato dos brancos e cruzamento das raças, etc. etc. (A AURORA FLUMINENSE $n$. 496, 17 jun. 1831).

Ainda, Meirelles enviou cartas a alguns líderes políticos citados por Silva como parte desta conspiração: Cipriano Barata, Francisco Sabino e ao Abade Grégoire. Nas cartas, perguntava se eles o conheciam e se os convidou para alguma sociedade. Cipriano

\footnotetext{
${ }^{16}$ Informações disponíveis em: Reis, Jacintho Rodrigues Pereira. Dicionário Histórico-Biográfico das Ciências da Saúde no Brasil (1832-1930). Capturado em 05/07/2020. Online. Disponível na Internet http://www.dichistoriasaude.coc.fiocruz.br/iah/pt/verbetes/reisjarope.htm.
}

Revista da ABPN • v. 12, n. Ed. Especial - Caderno Temático: "Africanos, escravizados, libertos biografias, imagens e experiências atlânticas" • agosto de 2020, p. $320-343$ 
Barata respondeu surpreso que não o conhecia e que um convite para qualquer sociedade seria uma loucura, posto que não eram amigos. A carta para o famoso religioso e revolucionário francês não foi enviada posto que chegou no país a notícia de seu falecimento. E não se recebeu uma resposta de Sabino antes da publicação do folheto em sua defesa. É importante ressaltar que Cipriano Barata e Francisco Sabino eram adversários políticos e que seria muito improvável que os dois se aliassem em uma mesma agremiação.

A intriga tinha como epicentro o Dr. Meirelles, porém, como foi acusado de instigar a revolta em escravizados, Jacintho Reis também publicou um folheto sobre o tema. Pardo, de família "pobre mas honrada", fora educado por um tio abastado e depois veio para o Rio de janeiro com seu irmão, assim o cirurgião se apresentava antes de iniciar a exposição de diversos documentos comprovando que não esteve na fazenda do Marquês de Baependi no período alegado por Silva em seu panfleto. Em sua exposição, Reis nos revelou as prováveis motivações e intenções da intriga. Ela estava inserida no âmbito das disputas políticas do primeiro reinado, sobretudo entre grupos liberais e a sua percepção sobre os portugueses no contexto da abdicação de D. Pedro I. Identificado como parte do grupo liberal exaltado, Silva atacava Meirelles e Jacintho devido as boas relações que os dois tinham com o governo imperial.

Vieira Fazenda em seu texto sobre a Sociedade Gregoriana, ao analisar o folheto escrito por Reis, concordara com a tese da disputa política:

Foram os exaltados os que, aproveitando-se da ignorância de Silva sobre o histórico das sociedades gregorianas, deram vasta circulação a tão sinistros boatos. Deles se aproveitaram as folhas da oposição para dar combate aos moderados, defensores do Governo Regencial (FAZENDA, 1927 p.300).

Jacintho Reis revelou uma outra faceta que foi deixada de fora do embate público. Seu cunhado mobilizava pessoas influentes da elite imperial, muitos deles brancos, para a organização de uma sociedade filantrópica promotora da educação. Seu objetivo seria proporcionar estudo à jovens pobres livres ou libertos e prepará-los para cursar "faculdades superiores", plano que foi paralisado devido a intriga. Lamentava então que Silva um "homem de cor, constitui-se pela calúnia o joguete dos inimigos de Meirelles.

Revista da ABPN • v. 12, n. Ed. Especial - Caderno Temático: "Africanos, escravizados, libertos biografias, imagens e experiências atlânticas" • agosto de 2020, p. $320-343$ 
De um projeto digno de aplauso, fizeram uma monstruosidade" (FAZENDA, 1927, idem).

$\mathrm{Na}$ justiça, o folheto difamatório teve sua impressão e circulação proibida, considerado calunioso. Entretanto, Silva foi inocentado. Meirelles, apesar de seus adversários políticos o acusarem de "haitianismo" sempre que lhes era oportuno ${ }^{17}$, continuou sob a órbita política do governo imperial. Sua nomeação como médico da imperial câmara era prova da confiança que os Orleans e Bragança depositavam nele.

Antes mesmo da nomeação, cuidava da saúde do jovem imperador e foi um dos liberais partidários da antecipação da maioridade que consultara o jovem Pedro II sobre sua ascensão ao trono imperial (FAZENDA, 1935 e LIBERALLI, 1969). Moreira de Azevedo também narrou em seu livro sobre as regências este fato, afirmando que "havia sido enviado. o Dr. Meirelles ao paço de São Cristovão, encarregado de saber do imperador a sua última palavra acerca da maioridade" (AZEVEDO, 1884, p.365). Podemos perceber então a sua participação ativa na antecipação da maioridade do imperador, atitude que lhe trouxe graves consequências políticas dois anos depois.

\section{A PRISÃO EM 1842}

Em 1842 acontecia a revolução liberal, com a ascensão do partido conservador ao poder. Uma das cidades mineiras amotinadas foi a cidade natal de Meirelles, local onde sua família gozava de algum reconhecimento. Meirelles preparava-se para presidir uma sessão da Academia Imperial de Medicina quando foi preso e pouco tempo depois enviado para a fragata Paraguaçu (Macedo, 1868; Souto, 1935) e no dia 2 de julho foi deportado para Portugal junto com Antônio Paulino Limpo Abreu (futuro Visconde de Abaeté), Francisco de Sales Torres Homem (futuro Visconde de Inhomerim), França Leite, José Francisco Guimarães e Geraldo Leite Bastos.

O próprio Meirelles anos depois narrou sua prisão em uma sessão do Parlamento. Ignorando o que acontecia naquele momento, "foi preso como um bandido que dorme às

${ }^{17}$ O folheto de Silva foi reimpresso em 1840, como era proibida sua impressão no Brasil, veio como impresso em Montevidéu. Segundo Vieira Fazenda, ele era reimpresso em períodos eleitorais e insinua que seus responsáveis eram os que disputavam representações políticas diretamente com Meirelles.

Revista da ABPN • v. 12, n. Ed. Especial - Caderno Temático: "Africanos, escravizados, libertos biografias, imagens e experiências atlânticas" • agosto de 2020, p. $320-343$ 
portas dos templos, levado a uma fortaleza, e depois de algumas horas passado a um navio prestes a fazer vela, e quase com a roupa do corpo mandado para um país estrangeiro" (ANNAES DO PARLAMENTO BRAZILEIRO, 1848 p. 264) Segundo o médico, seu nome nem constava da lista dos deportados. Não teve direito a seu salário, foi tratado como se não tivesse emprego ${ }^{18}$, recebendo apenas uma ajuda de "duas patacas por dia". Meirelles aceitou um empréstimo do agente brasileiro em Lisboa e partiu para Paris.

Em 14 de março de 1844 o Imperador concedeu anistia aos exilados e Meirelles retornou ao Brasil. Segundo Macedo "não houve juiz ou tribunal que o chamasse as contas e a restituição das honras e empregos desfez até a mais leve nuvem de suspeitas". De fato, o episódio não pareceu abalar sua credibilidade pública, pois Meirelles foi eleito deputado da assembleia provincial do Rio de Janeiro e logo depois, deputado da assembleia geral pela província de Minas Gerais (MACEDO, 1868). Atuou no parlamento até 1848, quando mais uma vez teve que confrontar insinuações sobre a Sociedade Gregoriana. Porém, neste momento Meirelles faz uma potente defesa de sua própria biografia, denunciando as perseguições que sofrera e apresentando, para constrangimento de boa parte dos parlamentares, o tratamento que é dado para homens negros que lutam por igualdade de direitos no Império.

\section{O RETORNO DO FANTASMA DO HAITI}

Em uma das acaloradas discussões em 1848, na sessão de 17 de junho, teve início no parlamento uma troca de acusações entre liberais e conservadores sobre as eleições em 1842. Em meio a comentários irônicos sobre os motivos da "paz" e "ordem" durante as eleições, Meirelles exclamou: "Nesse tempo eu estava em Paris bem tranquilo", fazendo alusão a sua prisão e deportação. Em resposta, o Deputado Pedro Chaves disparou: "É a ordem da Sociedade Haitiana" e este comentário exacerbou os ânimos dos parlamentares. Depois de pedidos de ordem, de aparte e ameaça de expulsão do deputado membro da bancada conservadora por seu linguajar inapropriado, esta teve continuidade.

Algumas sessões depois, Meirelles foi à tribuna discursar e em sua fala na sessão de 23 de junho, foi possível perceber o quanto ele construiu um discurso sobre a cidadania

\footnotetext{
${ }^{18}$ Meirelles naquele momento era professor da Escola de Belas Artes e médico da Imperial Câmara.

Revista da ABPN • v. 12, n. Ed. Especial - Caderno Temático: "Africanos, escravizados, libertos biografias, imagens e experiências atlânticas” • agosto de 2020, p. 320-343
} 
dos homens de cor no Império. Ao combater as antigas acusações de fundação de uma "sociedade haitiana", expôs uma ferida incômoda para as elites intelectuais e políticos do império, ao evidenciar o que considerava as intenções de quem o caluniara:

Sr. presidente, diz a constituição que são cidadãos brasileiros todos os que no Brasil tiverem nascido, quer sejam ingênuos ou libertos: que a lei será igual para todos, quer castigue, quer proteja; que recompensará em proporção dos merecimentos de cada um; que todos os cidadãos podem ser admitidos aos cargos públicos civis, militares, etc., sem outra diferença que não seja a dos seus talentos e virtudes (...) se são abolidos todos os privilégios, os privilégios de casta, só sustentados os que estão ligados a cargos por utilidade pública; como senhores, se proclama de boa-fé haitianismo no Brasil? Não se conhece pelo contrário que o que não quer o nobre deputado pelo Rio Grande, e os que como ele pensam é a execução da constituição do país, feita no país e para o país?

(...) Para excluir- se sistematicamente os cidadãos homens de cor que tem a seu favor o art, 169\$14, é que se chama sobre eles desconfianças aviltantes, fingindo terrores de massacres aéreos, inventados, urdidos e propalados pela soberba, pela intriga, pela perversidade, pela ignorância presunçosa.

Nada há, Sr. Presidente, para um mulato de brio e de honra, de mais aviltante, de mais insolente, de mais ignóbil, do que recear-se seja sinceramente, seja com hipocrisia, que os cidadãos homens de cor (com energia) se liguem a escravos (apoiados, muito bem) para obterem aquilo de que efetivamente gozam (apoiados, muito bem) sem revoluções de raças, sem massacres (apoiados, muito bem), como que os direitos que, a todos os brasileiros, a constituição deu aos homens de cor não sejam mais que suficientes para fazer a uns conter-se nos limites da obediência... e obrigar aqueles que os quiserem excluir do grêmio da sociedade de que fazem parte a serem justos e tolerantes, a executarem a constituição que não foi feita para eles sós! ${ }^{19}$ (ANNAES DO PARLAMENTO BRAZILEIRO, 1848, p. 265).

Este discurso no parlamento nos mostra que homens de cor livres não só tinham plena consciência de seus direitos como também é possível perceber pelo trecho o caráter coletivo de percepção deste direito. Meirelles não falava apenas por si, mas por todos os "homens de cor" livres. É provável que a origem dos rumores sobre a sociedade gregoriana, analisada pelo historiador Marco Morel, tivesse início justamente no fato de Meirelles ser reconhecido como um defensor da constituição, no que se refere aos direitos de negros livres e libertos e tornado público no incidente da divisão da enfermaria da Santa Casa entre doentes brancos e de cor (MOREL, 2017).

\footnotetext{
${ }^{19}$ Grifos do autor
}

Revista da ABPN • v. 12, n. Ed. Especial - Caderno Temático: "Africanos, escravizados, libertos biografias, imagens e experiências atlânticas” • agosto de 2020, p. $320-343$ 
Apesar do vocabulário político da primeira metade do século XIX, o discurso de Meirelles gerou muito desconforto tanto no parlamento, sobretudo nos representantes do governo. Acenos com a cabeça, pedidos de basta, comentários reprovando o debate ${ }^{20}$. Levantar questões sobre o tratamento desigual dado aos pretos e pardos livres era desconfortável para aquela elite política, sobretudo no contexto da escravidão. Pedro Chaves em sua réplica, tenta se esquivar desta acusação, dizendo que

o senhor deputado passou a questão para o que tinha de mais odioso, e supôs que eu tinha ofendido a uma classe, que eu a tinha atacado no seu melindre, e apresentou-se como campeão, tirando daqui tema para insultar-me (...) foi adiante, explicando o meu aparte de modo a tornar-se odioso a uma classe. (ANNAES DO PARLAMENTO BRAZILEIRO, 1848, p.277)

Em resposta Meirelles explicou detalhadamente a intriga sobre a Sociedade Gregoriana e demonstrou à plenária porque as insinuações de Pedro Chaves lhe eram ofensivas: "senhores, eu não creio que sejamos tão inocentes" logo em seguida afirma que desde 1831 "quando se fala em haitianismo, em sociedade haitiana, se não se refira tudo isto a Meirelles". Ele então explicou que o termo "haitianismo" era um grande logro, com o intuito de prejudicar politicamente pessoas como ele:

Os charlatães inventaram essa palavra, fizera, acreditar no paiz que existia uma sociedade de negros que eu era chefe, que tinha por fim destruir toda uma raça para substituí-la por outra. Este charlatanismo tem trazido a perversidade, tem constituído homens bons em feras, tem feito os maiores males possíveis... (Annaes do Parlamento Brazileiro, 1848, p.280)

Meirelles explicou que a situação sócio política brasileira era muito diferente da situação do Haiti, não existindo motivos reais para medo. E mais uma vez relatou os desdobramentos da publicação do panfleto de Silva, refutou as informações caluniosas e encerrou o discurso, contando sua trajetória até ali, em resposta à pergunta desdenhosa feita por Pedro Chaves: "mas senhores quem é esse homem?".

\section{A MARINHA}

\footnotetext{
${ }^{20}$ É possível acompanhar as reações da plenária lendo as notas taquigráficas da sessão parlamentar. Além dos aplausos e outras manifestações, também pelos comentários em apartes ou gritos dos outros deputados, que ficaram registrados nas atas.
}

Revista da ABPN • v. 12, n. Ed. Especial - Caderno Temático: "Africanos, escravizados, libertos biografias, imagens e experiências atlânticas" • agosto de 2020, p. $320-343$ 
Em 1849 Meirelles foi nomeado cirurgião-mor da Armada Nacional e Imperial. Provavelmente por sua carreira médica, mas também por apresentar no parlamento em 1848 o projeto que organizou o corpo de saúde da Armada. Chefiou o serviço de Saúde da Marinha por dezenove anos, até o fim de sua vida, em 1868. Dedicou-se também a seus pacientes, as reuniões da academia, e em 1850 foi nomeado para a Junta Central de Higiene Pública, criada no contexto da epidemia de Febre Amarela.

$\mathrm{Na}$ armada, como cirurgião mor procurou em diversas ocasiões junto ao governo melhores e mais justas condições de trabalho para os médicos da armada. Estes profissionais de saúde muitas vezes não eram considerados oficiais da marinha, ou eram desautorizados pelos comandantes (Licurgo Filho, 1991). Instituiu visitas sanitárias quinzenais em navios para evitar surtos de doenças, exigiu a vacinação contra a varíola em navios, quarteis e hospitais. Propôs escolas de ginástica e natação para criar condicionamento físico nos jovens marujos e modificações visando melhoria da alimentação. Apontou a necessidade de uniformes de acordo com o clima e estação do ano. Apresentou proposta para a mudança de local de hospitais, visando instalações com acomodações mais amplas e arejadas e em locais salubres. Sua atuação como Chefe do serviço de saúde da Armada foi muito significativa para a corporação, que o escolheu como patrono do Corpo de Saúde da Marinha de Guerra ${ }^{21}$.

Em 1858 foi promovido a chefe de divisão graduado, posto correspondente ao de contra-almirante. Mesmo em idade avançada Meirelles acompanhou o Imperador em sua viagem para o Rio Grande do Sul em setembro de 1865 para a rendição de Uruguaiana, durante a guerra do Paraguai. Estava com 68 anos, debilitado, mas insistiu em participar da comitiva "por dedicação a pessoa do imperador". Lá contraiu febre tifóide, e ficou gravemente doente e hemiplégico.

Neste período, Meirelles escreveu cartas ao Marquês de Olinda onde faz declarações indignadas sobre o processo de oficialização e definição de sua situação no serviço público. Solicitava ser efetivado no Posto de chefe de Divisão e a concessão do título de conselheiro. Além do intuito de fazer valer o que alegava merecer depois de

\footnotetext{
${ }^{21}$ Decreto federal no 63.684 de 25/11/1968.
}

Revista da ABPN • v. 12, n. Ed. Especial - Caderno Temático: "Africanos, escravizados, libertos biografias, imagens e experiências atlânticas" • agosto de 2020, p. $320-343$ 
tantos anos de serviço público em diversos cargos e funções ${ }^{22}$ sua grande preocupação era também conseguir deixar uma pensão melhor para sua filha solteira.

O esforço e obstinação expressos em algumas de suas declarações indignadas nessas cartas, podem de certa forma, dar pistas sobre as dificuldades enfrentadas pelo médico "homem de côr" para receber reconhecimento segundo o que considerava justo para si. Queixava-se, por exemplo, ao observar as concessões que se davam em favor de moços muito mais novos e menos experientes que ele. (Cunha, 2004)

Meirelles escreveu diversas cartas ao Marquês de Olinda, reclamando o título de conselheiro, entretanto não encontramos respostas aos seus pedidos. Seu filho, Saturnino Soares de Meirelles, foi agraciado com o título anos depois. O Cirurgião mor da Armada retornou ao Rio de Janeiro e no caminho, mesmo doente inspecionou os hospitais militares, conforme havia sido solicitado pelos Ministros da Guerra e da Marinha. Incansável, continuou cumprindo suas funções como acadêmico, médico e militar. Após agravamentos no quadro de saúde, morreu em 13 de julho de 1868.

\section{CONSIDERAÇÕES FINAIS}

Joaquim Candido Soares de Meirelles foi um intelectual envolvido com as turbulências políticas da primeira metade do século XIX na Corte Imperial. Sua ligação com o partido liberal e decisões políticas lhe renderam alianças e algumas amizades que o acompanharam por toda a vida. Também lhe renderam inimigos políticos, embates e entraves que produziram consequências em sua trajetória intelectual e em suas carreiras médica, política e militar.

Por parte da trajetória pessoal e profissional aqui exposta, podemos perceber o quanto a questão racial esteve presente na construção de sua carreira, como no incidente da Santa Casa de Misericórdia, a intriga da Sociedade Gregoriana e nos debates no parlamento em 1848. Meirelles em todas as ocasiões não deixou de se posicionar demarcando sempre a crença nos direitos de todos os pretos e mestiços livres à igualdade de direitos como qualquer outro cidadão brasileiro. Observamos em seus discursos que

\footnotetext{
2229 anos de serviço militar somados no exército e na Marinha, 20 anos como Lente de anatomia das paixões na Escola de Belas Artes, Médico da Imperial Câmara desde 1840, etc.
}

Revista da ABPN • v. 12, n. Ed. Especial - Caderno Temático: "Africanos, escravizados, libertos biografias, imagens e experiências atlânticas” • agosto de 2020, p. 320-343 
Meirelles sabia que estes direitos não eram usufruídos por todos de maneira igualitária. E podemos perceber isso em boa parte de sua agenda de reformas no serviço de saúde da marinha, com a condenação dos castigos físicos, nos discursos do parlamento e quando denuncia como a acusação de haitianismo servia para negar aos cidadãos de cor a garantia de igualdade de direitos perante a constituição do Império. E de forma indireta, a sua condição provavelmente se somou a outros fatores para que lhe fossem negadas promoções, cargos e títulos. Entretanto, costumava questionar aquilo que considerava injusto e pleitear as promoções que considerava ter direito.

A vida de Meirelles foi marcada por superações, determinação, estratégias de ascensão social e grandes êxitos. Também foi marcada por campanhas públicas de difamação, decepções e injustiças. Aspectos que constituíram a formação deste intelectual negro que esquecido às margens do tempo e da memória, o trazemos novamente ao centro da História, buscando reparar uma das injustiças Clio.

\section{REFERÊNCAIS BIBLIOGRÁFICAS}

AZEVEDO, Moreira de. História Pátria. O Brazil de 1831 a 1840. Rio de Janeiro: B.L.Garnier, 1884.

CARVALHO, Maria Alice R. Intelectuales Negros en el Brasil del Siglo XIX. In: Altamirano, Carlos; Myers, Jorge (org.). Historia de los Intelectuales em America Latina. Buenos Aires: Katz Editores, 2008, p. Buenos Aires: Katz Editores, 2008, p. 312-334.

FAZENDA, José Vieira. Antiqualhas e Memórias do Rio Antigo, vol.4. Rio de Janeiro: Imprensa Nacional, 1927.

FERNANDES, Reginaldo. O Conselheiro Jobim e o Espírito da Medicina do seu Tempo. Rio de Janeiro, Ed. Do Senado Federal, 1982.

FERREIRA, Luiz Otávio. José Francisco Xavier Sigaud: um personagem esquecido, uma obra reveladora. História, Ciências, Saúde-Manguinhos, Rio de Janeiro, v.V, n.1, p.125-126, mar./jun.1998.

FERREIRA, Luiz Otávio. O Nascimento de uma Instituição Científica: os periódicos médicos brasileiros da primeira metade do século XIX. Tese de doutorado, FFLCH-USP, Dept $^{\circ}$ de História, São Paulo, 1996.

Revista da ABPN • v. 12, n. Ed. Especial - Caderno Temático: "Africanos, escravizados, libertos biografias, imagens e experiências atlânticas" • agosto de 2020, p. $320-343$ 
GOMES, Flávio S. e DOMINGUES, Petrônio. Apresentação do Dossiê Temático Intelectuais Negros e Negras, Séculos XIX-XXI: desafios, projetos e memórias. Revista da ABPN・v. 10, n. 25・ mar - jun 2018, p.04-07

JOBIM, José Martins da Cruz. Dicionário Histórico-Biográfico das Ciências da Saúde no Brasil (1832-1930). Capturado em 28 nov. 2002. Online. Disponível na Internet http://www.dichistoriasaude.coc.fiocruz.br/iah/pt/verbetes/jobimjmcr.htm

KRAAY, Hendrik. Ritos políticos e politização popular no Brasil Imperial. Almanack. Guarulhos, n.09, p.19-40, abril de 2015

KURY, Lorelai. O Império dos Miasmas: A Academia Imperial de Medicina (18301850). Niterói, Dissertação de mestrado, Pós-graduação em História-Universidade Federal Fluminense, 1991.

LIBERALLI, Carlos Henrique. O Dr. Joaquim Candido Soares de Meirelles: médico e conspirador político. Revista do Instituto Histórico e Geográfico de São Paulo. Volume 69, São Paulo: 1971

LIMA, Silvio Cezar de Souza. Cruz Jobim e as doenças da classe pobre. O corpo escravo e a produção do conhecimento médico na Primeira metade do século XIX. Almanack, Guarulhos, n. 22, p. 250-278, Aug. 2019.

MACEDO, Joaquim Manoel de. 5 de novembro. Joaquim Cândido Soares de Meirelles. In: Anno Biographico Brazileiro. Rio de Janeiro: Typ. do Imprensa Instituto Artistico, 1876. p.364-368.

MACEDO, Joaquim Manoel de. Discurso. Revista do Instituto Histórico e Geográfico Brasileiro. T.XXXI, parte II, V.37, Rio de Janeiro, 1868

MEIRELLES, Joaquim Cândido Soares de. Dissertation sur les plaies d'armes a feu. Thèse présentée et soutenue à la Faculte de Médecine de Paris, lê 25 avril 1827, pour obtenir le grade de Docteur en chirurgie. A Paris, de L'Imprimerie de Didot Lê Jeune, Imprimeur de la Faculté de Médecine, rue dês Maçons-Sorbonne, nº13, 1827

MEIRELLES, Joaquim Cândido Soares de. Dissertation sur l'histoire de l'éléphantiasis. Thèse présentée et soutenue à la Faculte de Médecine de Paris, lê 10 janvier 1827, pour obtenir le grade de Docteur em médecine. A Paris, de L'Imprimerie de Didot Lê Jeune, Imprimeur de la Faculté de Médecine, rue dês Maçons-Sorbonne, nº13, 1827

MOREL, Marco. A Revolução do Haiti e o Brasil escravista. O que não deve ser dito. Jundiaí, SP: Paco, 2017.

MOREL. Marcos. O período das regências. (1831-1840). Rio de janeiro: Zahar, 2003

Revista da ABPN • v. 12, n. Ed. Especial - Caderno Temático: "Africanos, escravizados, libertos biografias, imagens e experiências atlânticas" • agosto de 2020, p. $320-343$ 
REIS, Jacintho Rodrigues Pereira. Dicionário Histórico-Biográfico das Ciências da Saúde no Brasil (1832-1930). Capturado em 05/07/2020. Online. Disponível na Internet http://www.dichistoriasaude.coc.fiocruz.br/iah/pt/verbetes/reisjarope.htm.

SANTOS FILHO, Lycurgo de Castro. História Geral da Medicina Brasileira. SP, Brasiliense, 1991.

SIGAUD, José Francisco Xavier. Capturado em 28 nov. 2002. Online. Disponível na Internet http://www.dichistoriasaude.coc.fiocruz.br/iah/pt/verbetes/sigjoxav.htm

SOUTO, Luiz Felipe Vieira. Soares de Meireles: contribuições para a sua biografia. RIHGB, RJ, Imprensa Nacional, 1935.

SOUZA, Luis Castro de. Joaquim Candido Soares de Meirelles e o Instituto Histórico e Geográfico Brasileiro. Revista do Instituto Histórico e Geográfico Brasileiro. Volume 296, Rio de Janeiro, 1972.

SOUZA, Luis Castro de. Soares de Meirelles e a França. Revista do Instituto Histórico e Geográfico Brasileiro. Volume 147, n. 350 Rio de Janeiro, 1986.

\section{PERIÓDICOS:}

Annaes do Parlamento Brazileiro, Rio de Janeiro, 1848.

Astréa, Rio de Janeiro, 1828.

Aurora Fluminense, Rio de Janeiro, 1831.

Semanário de Saúde Pública, Rio de Janeiro, 1831.

Recebido 03/07/2020

Aprovado em 29/07/2020

Revista da ABPN • v. 12, n. Ed. Especial - Caderno Temático: "Africanos, escravizados, libertos biografias, imagens e experiências atlânticas" • agosto de 2020, p. $320-343$ 